Review

\title{
Fourier Transform Infrared (FTIR) Spectroscopy to Analyse Human Blood over the Last 20 Years: A Review towards Lab-on-a-Chip Devices
}

\author{
Ahmed Fadlelmoula ${ }^{1,2}$, Diana Pinho ${ }^{3} \mathbb{D}$, Vitor Hugo Carvalho ${ }^{4,5} \mathbb{D}$, Susana O. Catarino ${ }^{1,2} \mathbb{D}$ \\ and Graça Minas $1,2, *$ (D) \\ 1 Center for MicroElectromechanical Systems (CMEMS-UMinho), University of Minho, \\ 4800-058 Guimaraes, Portugal; id9247@alunos.uminho.pt (A.F.); scatarino@dei.uminho.pt (S.O.C.) \\ 2 LABBELS-Associate Laboratory, Braga/Guimaraes, Portugal \\ 3 International Iberian Nanotechnology Laboratory (INL), 4715-330 Braga, Portugal; diana.pinho@inl.int \\ 4 Algoritmi Research Center, University of Minho, 4800-058 Guimaraes, Portugal; vcarvalho@ipca.pt \\ 5 2Ai, School of Technology, IPCA, 4750-810 Barcelos, Portugal \\ * Correspondence: gminas@dei.uminho.pt
}

check for

updates

Citation: Fadlelmoula, A.; Pinho, D.; Carvalho, V.H.; Catarino, S.O.; Minas, G. Fourier Transform Infrared (FTIR) Spectroscopy to Analyse Human Blood over the Last 20 Years: A Review towards Lab-on-a-Chip Devices. Micromachines 2022, 13, 187. https://doi.org/10.3390/

mi13020187

Academic Editor: Nam-Trung Nguyen

Received: 31 December 2021

Accepted: 24 January 2022

Published: 26 January 2022

Publisher's Note: MDPI stays neutral with regard to jurisdictional claims in published maps and institutional affiliations.

Copyright: () 2022 by the authors. Licensee MDPI, Basel, Switzerland. This article is an open access article distributed under the terms and conditions of the Creative Commons Attribution (CC BY) license (https:/ / creativecommons.org/licenses/by/ $4.0 /)$.

\begin{abstract}
Since microorganisms are evolving rapidly, there is a growing need for a new, fast, and precise technique to analyse blood samples and distinguish healthy from pathological samples. Fourier Transform Infrared (FTIR) spectroscopy can provide information related to the biochemical composition and how it changes when a pathological state arises. FTIR spectroscopy has undergone rapid development over the last decades with a promise of easier, faster, and more impartial diagnoses within the biomedical field. However, thus far only a limited number of studies have addressed the use of FTIR spectroscopy in this field. This paper describes the main concepts related to FTIR and presents the latest research focusing on FTIR spectroscopy technology and its integration in lab-on-a-chip devices and their applications in the biological field. This review presents the potential use of FTIR to distinguish between healthy and pathological samples, with examples of early cancer detection, human immunodeficiency virus (HIV) detection, and routine blood analysis, among others. Finally, the study also reflects on the features of FTIR technology that can be applied in a lab-on-achip format and further developed for small healthcare devices that can be used for point-of-care monitoring purposes. To the best of the authors' knowledge, no other published study has reviewed these topics. Therefore, this analysis and its results will fill this research gap.
\end{abstract}

Keywords: blood cells; fourier transform infrared (FTIR) spectroscopy; functional group; lab-on-a-chip

\section{Introduction}

Millions of blood test analyses are performed every day worldwide in order to provide blood diagnostic services for the patients [1]. Usually, these tests are performed in clinical laboratories, simultaneously using different devices and relying on different specialties [2]. These devices are needed to run routine blood tests [2] and examine multiple parameters to assist the physicians in haematology-, chemistry-, and immunology-related diagnosis, among others. They require human resources, dedicated facilities, and time, which, in an ideal device, should be less than one hour from taking a sample to printing out the results [3,4]. Moreover, the reagents needed to run all these tests are expensive, and most of them are toxic, having a significant direct and indirect effect on the environment [5].

Diagnostic devices currently available on the market rely on the same measuring techniques developed in the last century (mainly spectrophotometry or electrochemical assays) [6]. Meanwhile, viruses, bacteria, and fungi are rapidly evolving [7], pushing further the need to develop new, quick, and reliable diagnostic tools. The primary, commercially available measuring techniques for such devices are spectrophotometry, enzyme-linked 
immunosorbent assay (ELISA), electrophoresis, and blood cell counting or complete blood count (CBC). However, all of these methods have limitations. In ultraviolet-visible (UVVIS) spectrophotometry, the main limitation is the requirement for sample and setup preparation time to avoid light interferences [8]. ELISA limitations are related to the cost of the assays due to the use of antibodies, the risk of cross-reactivity, the high background noise, and extended analysis time [9]. Electrophoresis requires a large sample for the assays, as well as high analysis precision [10]. Finally, CBC limitations are related to the manual examination of blood smears, difficulty recognising abnormal red cell shapes (such as fragmented cells), and high running costs [11]. Hence, the pressing need for new, fast, and precise analysing techniques.

Fourier transform infrared (FTIR) spectroscopy is a field that has undergone significant development over the past decade, promising easier, more rapid, and more objective diagnoses [12,13]. FTIR spectroscopy studies the interactions between matter and electromagnetic radiation that appear in the form of a spectrum. Each molecule has a spectrum fingerprint that makes it unique and allows it to be distinguished from other molecules [14]. FTIR spectroscopy is also an effective and nondestructive method for monitoring cellular alterations $[15,16]$. FTIR spectral analysis has allowed the characterisation of several organs' diseases, as well as the quantification of different biomolecules such as proteins [16], nucleic acids [17,18], and lipids [19]. Several research documents highlighting the importance of spectroscopic techniques in cancer detection have been published in the literature $[15,20,21]$. FTIR focuses on the differentiation and characterisation of cells and tissues by looking at individual bands or groups to precisely identify the molecular conformations, bonding types, functional groups, and intermolecular interactions that compose the specimen [13,20]. Thus, this paper describes the main concepts and terminologies related to FTIR and presents the latest published research focusing on FTIR spectroscopy technology and its integration in lab-on-a-chip devices for application in the biological field. To the best of the authors' knowledge, no other studies have reviewed these topics, making this review the first to fill this research gap.

The paper is organised into five sections. Section 1 presents an introductory overview and the primary motivation guiding the study. Section 2 presents FTIR spectroscopy's theoretical, conceptual elements and clarifies the salient terminology, including the concepts of infrared (IR) regions, radiation, molecular vibration, FTIR, and Michelson Interferometer. Section 3 describes the methods used in the presented study, while Section 4 offers the results of the analysis of twenty-year-long research on the application of FTIR spectroscopy in the biological field, focusing on the possibility of applying this technology in lab-on-achip devices. Finally, Section 5 presents the conclusion and future trends.

\section{Theoretical Considerations}

Here the terminologies and concepts associated with FTIR spectroscopy, namely the IR region, IR radiation and molecular vibrations in biological matters, FTIR techniques and Michelson interferometer, are presented.

\subsection{Infrared Region}

IR radiation is a group of electromagnetic waves (EMR) with wavelengths longer than visible radiation, invisible to the human eye. The IR region of the electromagnetic spectrum ranges in wavelengths from $0.8-100 \mu \mathrm{m}$, illustrated in Table 1 [22,23]. Typically, the IR is broken into three ranges, near-IR, mid-IR, and far-IR. Most of the IR used in medical applications are in the mid-IR range, considering radiation from the electromagnetic spectrum, in the wavenumber interval from $4000 \mathrm{~cm}^{-1}$ to $400 \mathrm{~cm}^{-1}$. The frequency of the absorbed radiation is responsible for each subatomic vibrational interaction, as schematised in Figure 1. 
Table 1. InfraRed Regions [22,23].

\begin{tabular}{cccc}
\hline Region & Wavelength $(\boldsymbol{\mu m})$ & Wavenumbers $\left(\mathbf{c m}^{-\mathbf{1}}\right)$ & Frequency $\left(\times \mathbf{1 0}^{\mathbf{1 4}} \mathbf{H z}\right)$ \\
\hline Near-IR & $0.8-2.5$ & $12,500-4000$ & $3.75-1.2$ \\
Mid-IR & $2.5-25$ & $4000-400$ & $1.2-0.12$ \\
Far-IR & $25-100$ & $400-100$ & $0.12-0.03$ \\
Frequently Used & $2.5-15$ & $4000-670$ & $1.2-0.20$ \\
\hline
\end{tabular}

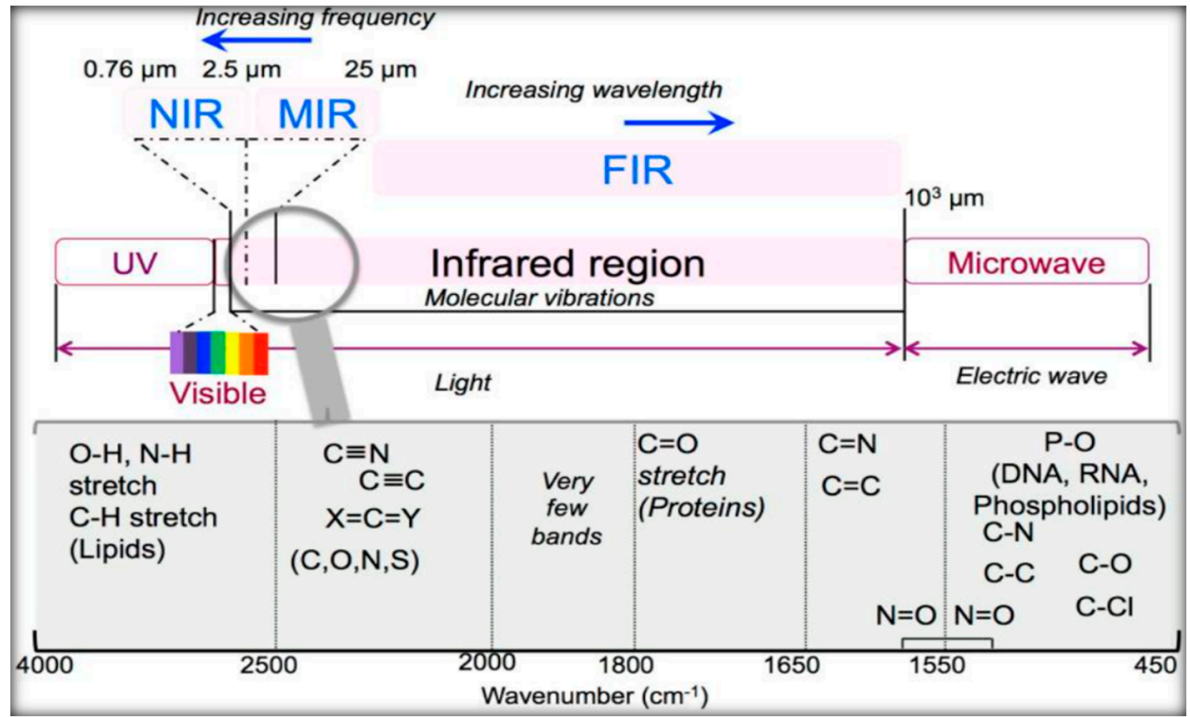

Figure 1. Scheme of the optical spectrum, focusing on the infrared region. Reprinted from [23], MDPI, under a Creative Commons Attribution (CC BY) license.

\subsection{IR Radiation and Molecular Vibrations in Biological Matter}

As a type of electromagnetic wave, IR propagates energy and momentum, with properties similar to both a wave and a particle- the photon. IR is emitted or absorbed by molecules as they change their rotational, vibrational motions. It excites wave modes in a molecule by changing them instantaneously, making it a helpful frequency variation for studying the molecular energy states with correct symmetry. Therefore, IR chemical analysis studies the absorption and transmission of photons in the IR region [24]. The IR spectrum of biological samples consists of a combination of the characteristic absorption bands of proteins, lipids, nucleic acids, and carbohydrates within that sample [25,26].

The protein absorption bands are often assigned to amino acid side groups or peptide backbone in the $1700 \mathrm{~cm}^{-1}-1500 \mathrm{~cm}^{-1}$ range. The vibrational modes of the peptide backbone produce the amide I and II bands. The amide I band $\left(1700 \mathrm{~cm}^{-1}-1600 \mathrm{~cm}^{-1}\right)$ is mainly associated with the bending vibration of the $\mathrm{N}-\mathrm{H}$ bond. The bands of amides I and II are usually used to analyse the secondary protein structure [27]. The presence of absorption bands at $1450 \mathrm{~cm}^{-1}$ and $1400 \mathrm{~cm}^{-1}$ is due to asymmetric and symmetric methyl bending modes, respectively [28].

In the spectra of lipids, absorption bands are found in numerous spectral regions: the range of $3050 \mathrm{~cm}^{-1}-2800 \mathrm{~cm}^{-1}$ for asymmetric and symmetric stretching vibrations of $-\mathrm{CH} 2$ and $-\mathrm{CH} 3$, the range of $1500 \mathrm{~cm}^{-1}-1350 \mathrm{~cm}^{-1}$ for deformation vibrations of $-\mathrm{CH} 2$ and -CH3 from the acyl chains of lipids, the range of $1745 \mathrm{~cm}^{-1}-1725 \mathrm{~cm}^{-1}$ for symmetric stretching vibrations of ester-carbonyl bond $(\mathrm{C}=\mathrm{O})$, and the range of $1270 \mathrm{~cm}^{-1}-1000 \mathrm{~cm}^{-1}$ for odd $\left(1240 \mathrm{~cm}^{-1}\right)$ and symmetric $\left(1080 \mathrm{~cm}^{-1}\right)$ vibrations of -PO2- in phospholipids [29]. The IR spectra of nucleic acids are characterised in four spectral regions: the region of $1780 \mathrm{~cm}^{-1}-1550 \mathrm{~cm}^{-1}$ for in-plane vibrations of double bonds of bases, the region of $1550 \mathrm{~cm}^{-1}-1270 \mathrm{~cm}^{-1}$ for the deformation vibrations of bases that include the sugar vibrations, the region of $1270 \mathrm{~cm}^{-1}-1000 \mathrm{~cm}^{-1}$ for vibrations of -PO2- and, finally, the region of $1000 \mathrm{~cm}^{-1}-780 \mathrm{~cm}^{-1}$ for the vibrations of the sugar-phosphate backbone [30]. The carbohy- 
drate spectra contain bands in the following ranges: the region of $3600 \mathrm{~cm}^{-1}-3050 \mathrm{~cm}^{-1}$ is assigned to the stretching vibration of $\mathrm{O}-\mathrm{H}$, the range of $3050 \mathrm{~cm}^{-1}-2800 \mathrm{~cm}^{-1}$ to the stretching vibrations of $-\mathrm{CH}_{3}$ and $-\mathrm{CH}_{2}$, the region of $1200 \mathrm{~cm}^{-1}-800 \mathrm{~cm}^{-1}$ to the stretching vibrations of the $\mathrm{C}-\mathrm{O} / \mathrm{C}-\mathrm{C}$ species, and, finally, the $1500 \mathrm{~cm}^{-1}-1200 \mathrm{~cm}^{-1}$ relates to the deformational modes of the $\mathrm{CH}_{3} / \mathrm{CH}_{2}$ species [31]. In the blood analysis applications, the spectral bands of $3000 \mathrm{~cm}^{-1}-2800 \mathrm{~cm}^{-1}$ are the most relevant ones for analysing red blood cells and platelets, while for the white blood cells, the most relevant band ranges are $513 \mathrm{~cm}^{-1}-1445 \mathrm{~cm}^{-1}$. Thus, those targeted cells and corresponding spectral bands are the most used for blood analysis, particularly lab-on-a-chip applications.

\subsection{Fourier Transform Infrared Spectroscopy (FTIR) Techniques}

FTIR spectroscopy is a technique used to obtain the absorption or emission infrared spectrum of a solid, liquid, or gas [14,32]. The FTIR spectrometer simultaneously collects high-resolution information over a wide spectral range (between 4000 and $400 \mathrm{~cm}^{-1}$ ), a distinct advantage over a dispersive spectrometer, which estimates power over a narrow range of frequencies at once. The aim of spectroscopy techniques (FTIR or bright perceptible (UV-Vis) spectroscopy) is to quantify how much light a sample absorbs at each frequency [14]. The most direct approach, the "dispersive spectroscopy" method, consists of focusing a monochromatic light beam at a sample, measuring the amount of absorbed light, and recalculating it for each frequency [14]. Fourier transform spectroscopy is a less instinctive approach for obtaining similar data. Rather than focusing a monochromatic (single frequency) light emission at the sample, this strategy might focus a bar, or array, which contains numerous frequencies of light at once and measures how much of that beam is absorbed by the sample. Then, the wave is changed to contain a different mixture of frequencies giving a second data point. This cycle is repeated many times within a short period of time, and the information is acquired by a computer. For instance, the wave plotted in Figure 2, called an interferogram, is created by applying a broadband light source-one that contains the entire range of frequencies to be estimated. The light sparks into a Michelson interferometer (detailed in the next section), consisting of a special array of mirrors, one of which is moved by a motor. As this mirror moves, each light frequency in the column is occasionally obstructed, mediated, impeded, and transmitted by the interferometer. The different frequencies are tweaked at different rates so that the column exiting the interferometer has a different range at each second or mirror position [14,32].

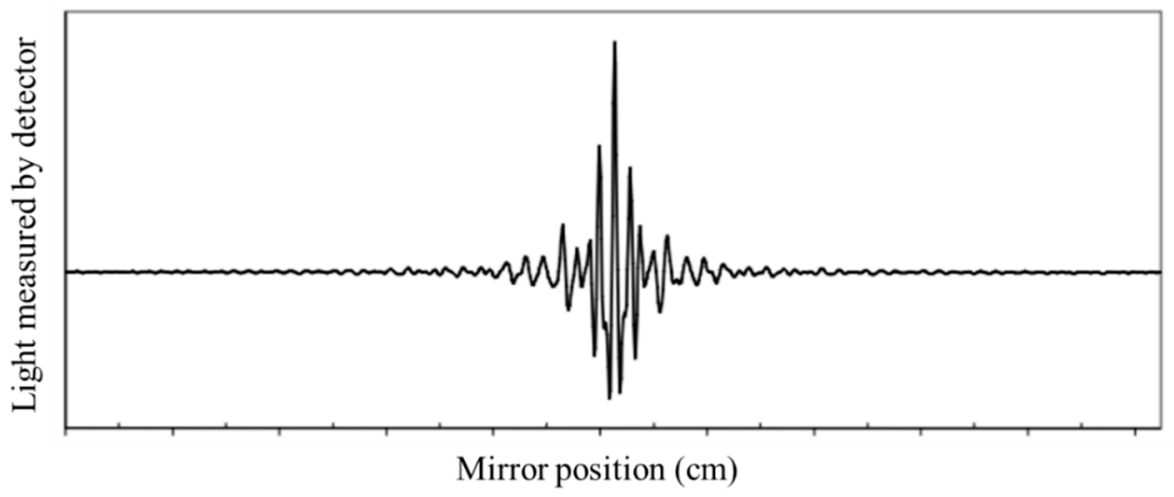

Figure 2. Example of a general FTIR interferogram. The central peak is positioned at the ZPD position (zero path difference or zero retardation), where the maximal amount of light passes through the interferometer to the detector.

Computational postprocessing based on Fourier frequencies is required to calculate the results (light pickup for each frequency) from the coarse raw information (light pickup for each mirror position), as presented in the example of Figure 2 [14,32]. Then, the Fourier transform converts a space (for this situation, the mirror's distance in $\mathrm{cm}$ ) into its opposite space (wavenumbers in $\mathrm{cm}^{-1}$ ). 
The main limitations of FTIR spectroscopy relate to the tissue depth penetration of the infrared light, which only allows biochemical analysis of the tissues up to a few dozens of micrometres [20]. Additionally, in the conventional FTIR spectroscopy, which works in transmission mode and consequently with no incidence angle between emitter and sample, there is difficulty in assuring the reproducibility of the spacer thickness when using liquid samples [33].

The attenuated total reflectance Fourier transform (ATR -FTIR) technique as a complementary technique has helped FTIR spectroscopy overcome this limitation. ATR-FTIR is a particular FTIR spectroscopy method, which measures the reflected signal from a sample. In this reflectance setup, the IR radiation passes through a crystal with a high refractive index (typically with an angle of $45^{\circ}$ ) and undergoes total internal reflection before exiting the crystal and being directed to an IR detector $[33,34]$. ATR-FTIR has a lower penetration depth than conventional FTIR (around $200 \mathrm{~nm}$ ) but, since it measures the reflected light, it is an adequate method for measuring high absorbing and high thickness samples that typically do not allow the transmission of IR radiation [33]. Additionally, this technique can direct measurements of gas, fluidic and thin-film solid-state samples without complex sample preparation and with enhanced surface sensitivity [33,34].

Finally, microscopic FTIR (micro-FTIR) [35] relates to another particular FTIR technique that couples an IR spectrometer to a visible light microscope in order to achieve better sensitivity when detecting condensed-phase compounds [36] and is adequate for measuring solid or liquid thin films samples. In this technique, the microscope focuses the IR laser beam on the sample, and the measurement mainly comes from the target focal point, meaning that even a short displacement in the laser beam or the sample could provide a significant difference in the results. Therefore, micro-FTIR distinguishes by allowing local measuring of a particular point in the sample, while the conventional FTIR gives the average information from a complete homogenised sample $[35,36]$.

Besides helping to identify organic compounds based on their specific IR spectral fingerprint, FTIR also has a relevant role in detecting alterations or pathological states of the molecules and samples, leading to different spectra between patients and healthy controls, as presented in several examples in Section 4. In the presence of pathology, the IR spectrum of a sample will change, either by changing its intensity or shifting its peak frequencies [37]. These shifts can be due to multiple chemical alterations in the molecules' composition, including weakening of the bonds, decreasing mass of the molecules, or even shifting the stretching vibrations due to temperature variations, which will change the vibrational frequencies of the bands. More details on this can be found elsewhere [37].

\subsection{Michelson Interferometer}

The Michelson Interferometer technique was adapted for FTIR so that the light from the polychromatic IR source, effectively a blackbody radiator, is collimated and directed onto a beam splitter, with $50 \%$ of the photons by the fixed mirror and $50 \%$ transmitted by the movable mirror [32]. In this configuration, light is reflected from the two mirrors back to the beam splitter, and some fraction of the original light passes into the sample compartment Figure 3.

There, the light is focused on the sample. When leaving the sample compartment, the light is refocused on the detector. The difference in the optical path length between the two mirrors to the interferometer is known as the retardation or optical path difference (OPD) [32]. An interferogram (as in Figure 2) is obtained by varying the retardation and recording the signal from the detector for different retardation values. When no sample is present, the interferogram profile depends on the variation of the source intensity and splitter efficiency with wavelength. This results in a maximum at zero retardation when there is constructive interference at all wavelengths, followed by a series of wiggles [32]. This problem is critical in the case of zero default when there is constructive interference within the smallest wavelengths followed by a series of wigglers. The location of the null default is determined by locating the purpose of the excessive intensity within the 
interferogram. When a pattern is given away, the course interferogram is modulated with the aid of the absorption bands within the pattern (as exemplified in Figure 3) [32].



(a)



(b)

Figure 3. Schematic diagram of a Michelson interferometer configured for FTIR. (a) An ideal Michelson interferometer; (b) a Michelson interferometer with the movable mirror tilting. The continuous and dashed lines represent the different directions of light. Reprinted from [32], MDPI, under a Creative Commons Attribution (CC BY) license.

\section{Methods}

The research and data collecting strategy was based on evaluating a wide scale of papers (matching the topic keywords) published in the FTIR spectroscopy field, in the last decades, with all adequate reference and copyright permissions. For that, a comprehensive electronic search on ScienceDirect, Scopus and PubMed databases was performed (up to October 2021, Q3), as well as a direct search on different publishers' specific databases, such as MDPI, Wiley, or Nature, among others. Search keywords included: FTIR, spectroscopy, optics, infrared, blood, blood cells, Functional Group, Michelson Interferometer, lab-on-achip, microfluidics, microdevice and diagnostics. The search strategy was established by combining several keywords and using AND/OR Boolean operators. The relevant studies resulting from the database search were manually analysed to identify other potential studies to be included. The exclusion criteria were: reviews, comments, overviews, case reports, viewpoints and perspectives, as well as documents reporting tests with data ambiguity. Studies not written in the English language were also excluded, as well as duplicate results. From there, titles and abstracts were screened. All abstracts were read, and those that did not fit the purpose of this review were excluded. The information regarding the application, quantitative outcomes, reported study limitations, and other relevant comments were selected and extracted from the remaining articles. Specifically, the authors selected papers that reported FTIR spectroscopy for analysing between normal blood samples and pathological blood samples for cancer detection, HIV early recognition in pregnant women, and blood grouping identification, among others. These applications were chosen to illustrate the wide range of FTIR applications. Finally, the most important conclusions and limitations on the analysed papers were summarised.

\section{Results}

This section presents the data collection results examining the most relevant studies over the last twenty years addressing FTIR in the biological field, organised by their application field.

\subsection{Collection of Data Seeking Applications of FTIR Spectroscopy}

FTIR is widely used as a diagnostic method to analyse different materials and samples. According to the PubMed search results, FTIR spectroscopy was first studied as a new potential method in 1972, and until now (2021, Q3), more than 76,900 papers have been published on FTIR spectroscopy. A few years later, in 1982, researchers in the biological 
field recognised the potential of the FTIR techniques and their suitability for diagnostics, including diagnoses of a long list of diseases that included cancer, microbes, bacteria, and viruses detection. The number of papers relating to FTIR published in the biological field in 2021 (up to Q3) is around 4810. Figure 4a,b illustrate the evolution of FTIR studies over the last two decades.



(a)

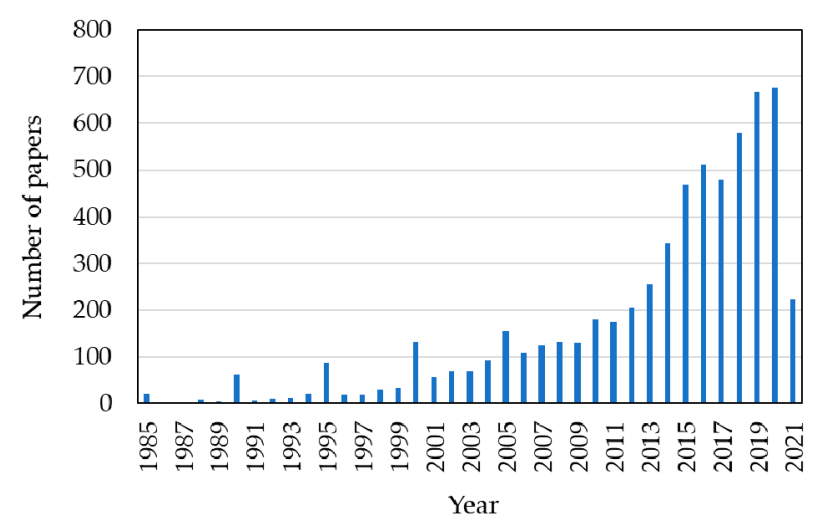

(b)

Figure 4. Published papers focusing FTIR: (a) Overall papers, since 1972; (b) papers in the biological field, since 1985 (until 2021, Q3).

In particular, by analysing the PubMed search results, a short number of papers addressed the use of FTIR spectroscopy to analyse and distinguish between normal blood sample cells and pathological blood samples. From the research undertaken until 2021, this number is less than 100 (Figure 5).

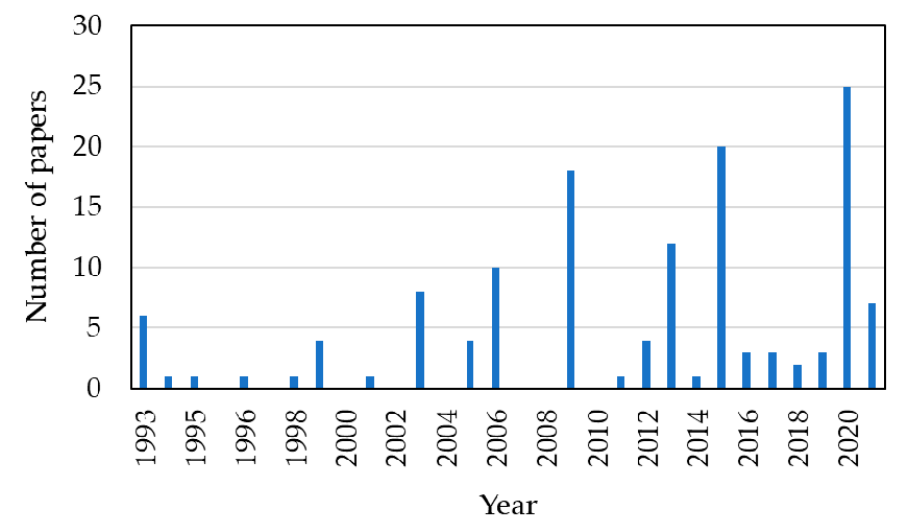

Figure 5. Published papers focusing FTIR for addressing differentiation between normal/pathological blood samples, from 1999 until 2021 (Q3).

Figure 6 summarises the number of published papers considering the FTIR subject (total of 76,900 papers) and its specificity in the application of the biology domain (4810) and subdomain for distinguishing between normal and pathological blood samples (around 100). 




Area of the paper

Figure 6. Summary of the total published papers focusing FTIR from 1999 until 2021 (Q3).

\subsection{Applications of FTIR Spectroscopy in Cancer Diagnosis}

Among the different spectroscopic techniques developed to distinguish between normal and cancerous blood tissues, Fourier transformed spectroscopy has shown tremendous potential. Additionally, biomedicine's IR-based techniques have become a reality with a large amount of information accumulated from clinical studies, trials, and developments [38-40].

In 2013, FTIR spectroscopy was applied to study healthy and cancerous blood samples, using a diffuse reflectance technique from SHIMADZU 8000 series FTIR spectrophotometer. The spectra of cancerous and healthy blood were registered at a resolution of $4 \mathrm{~cm}^{-1}$ in the region of $900 \mathrm{~cm}^{-1}$ to $2000 \mathrm{~cm}^{-1}$, as observed in Figure 7a. The obtained results show that the bands of proteins, lipids, carbohydrates, and nucleic acids from cancerous samples are clearly different from the normal ones dominated by two absorption bands at $1643 \mathrm{~cm}^{-1}-1550 \mathrm{~cm}^{-1}$, known as amide I and amide II. Amide I appears from the $\mathrm{C}=\mathrm{O}$ stretching vibrations and amide II from the $\mathrm{C}-\mathrm{N}$ stretching and $\mathrm{CNH}$ bending vibrations. This wavelength band looks strong and sharp in a healthy blood sample [38], as seen in Figure $7 \mathrm{~b}$.



(a)

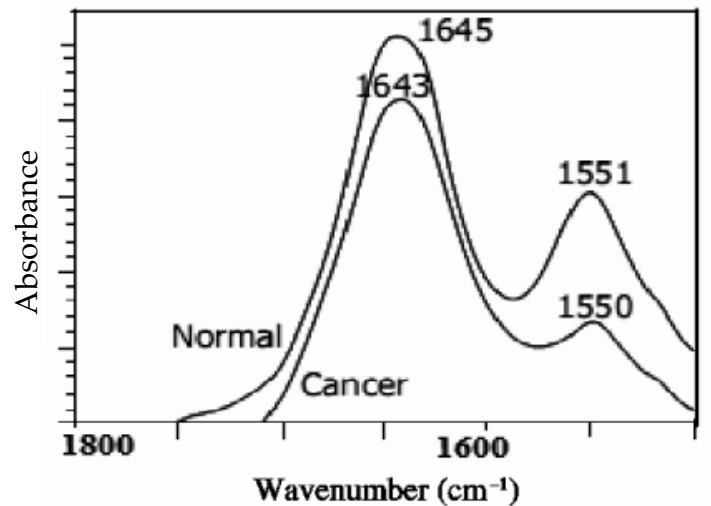

(b)

Figure 7. (a) FTIR absorption spectra of ' $a$ ' cancerous blood, 'b' normal blood and ' $c$ ' water samples using air as a reference; (b) detail of the FTIR absorption spectra of the normal and cancerous blood. Reprinted from [38], Copyright 2010 Convener, MMSETLSA-2009, with permission from the authors.

In 2016, label-free FTIR was used for early cancer detection in blood samples. This technique allowed detecting and verifying spectral biomarker candidate patterns to detect non-small cell lung carcinoma (NSCLC). The study was conducted on 161 patients where 
blood serum and plasma samples were analysed using an automatic FTIR spectroscopic system, together with pattern recognition algorithms, such as Monte Carlo cross-validation, linear discriminant analysis and random forest classification. Marker patterns for cancer discrimination (both from squamous-cell carcinoma and adenocarcinoma patients) from clinically relevant disease control patients were identified in FTIR spectra of blood samples. The analysis was constrained to the respective C-H-stretching in the $2800 \mathrm{~cm}^{-1}-3200 \mathrm{~cm}^{-1}$ region and the fingerprint regions $1750 \mathrm{~cm}^{-1}-875 \mathrm{~cm}^{-1}$ [39]. Accuracy of up to $79 \%$ was recorded [39]. According to the authors, the study demonstrates the applicability of FTIR spectroscopy using blood for lung cancer detection. Evidence for cancer subtype discrimination was given. With improved performance, the method could be developed as a routine diagnostic tool for blood testing of NSCLC [39].

Another study from 2018 demonstrated that ATR-FTIR spectroscopy is a potential technique that can be used for cutaneous melanoma (i.e., skin cancer) diagnosis and for differentiating the metastatic potential of cancer cells. By using IR spectroscopy, one can identify various types of cancer such as basal cell carcinoma, malignant melanoma, nevus, as well as metastatic potential by evaluating the alterations in hydration level and molecular changes [40]. The spectra obtained by the authors show different intensities and frequencies of normal and cancerous samples in the spectral range between $4000 \mathrm{~cm}^{-1}$ and $400 \mathrm{~cm}^{-1}$. The region between $4000 \mathrm{~cm}^{-1}$ and $3000 \mathrm{~cm}^{-1}$ shows stretching vibrations of $\mathrm{O}-\mathrm{H}$ and $\mathrm{N}-\mathrm{H}$ corresponding to the spectral bands of collagens and proteins of the skin. As cancer changes, the permeability of the cells' membrane and the metastatic potential also change with the hydration grade of the cell membrane; the ATR-FTIR spectroscopy is an approach that allows successful differentiation of the metastatic potential of cancer cells [40]. In particular, the comparison between fewer and more metastatic cells shows that the hydration level of the plasma membrane leads to a significant difference between both states of cancer [40].

A study from 2020 presented an easy to use, a reagent-free method based on (ATRFTIR) spectroscopy to quantify the protein content of extracellular vesicles (EV) samples with no sample preparation [41]. After calibration with bovine serum albumin, the protein concentration of red blood cell-derived EVs (REVs) was investigated by ATR-FTIR spectroscopy. The integrated region of the amide I band was calculated from the IR spectra of REVs, which was proportional to the protein quantity in the sample. Discriminatory protein bands of amide A, amide I and amide II were set at 3298, 1657, and $1546 \mathrm{~cm}^{-1}$, respectively. In the reported study, vibrations corresponding to the lipid components were also witnessed as antisymmetric and symmetric methylene stretching of acyl chains in the range $2924 \mathrm{~cm}^{-1}$ to $2850 \mathrm{~cm}^{-1}$, and the $\mathrm{C}=\mathrm{O}$ stretching at $-1738 \mathrm{~cm}^{-1}$ of the glycerol esters, respectively [41], as shown in Figure 8.

This new method presents a reagent-free alternative to traditional colourimetric protein determination assays and requires no special sample preparation to investigate EVs [41]. Therefore, this IR spectroscopy-based protein quantification method can be successfully adapted to the routine analysis of extracellular vesicles.

FTIR was also used to detect biomarkers for early screening of pediatric leukaemia [42]. In the reported study, the spectra were acquired from blood serum samples of ten child patients with B-cell precursor lymphoblastic leukaemia (BCP-ALL) and were contrasted with ten control samples. No clear peak shift was spotted between the averaged spectra of leukaemia patients and healthy individuals at the first trial. Thus, the authors applied the ratios of particular corrected peaks heights and the second derivatives analytical approaches to better distinguish between BCP-ALL and the control sample. A significant shift was observed for the peak corresponding to the amide I band $\left(1700 \mathrm{~cm}^{-1}\right.$ to $\left.1600 \mathrm{~cm}^{-1}\right)$ due to the $\mathrm{C}=\mathrm{O}$ stretch vibrations of the peptide linkages. The frequencies of the amide I band are originally fixed to the secondary structure of the proteins. The position of the amide I band was at $1645 \mathrm{~cm}^{-1}$ in the FTIR spectrum of the control group, whereas for the BCP-ALL patients, the peak was shifted to $1641 \mathrm{~cm}^{-1}$ [42], as seen in Figure 9. 

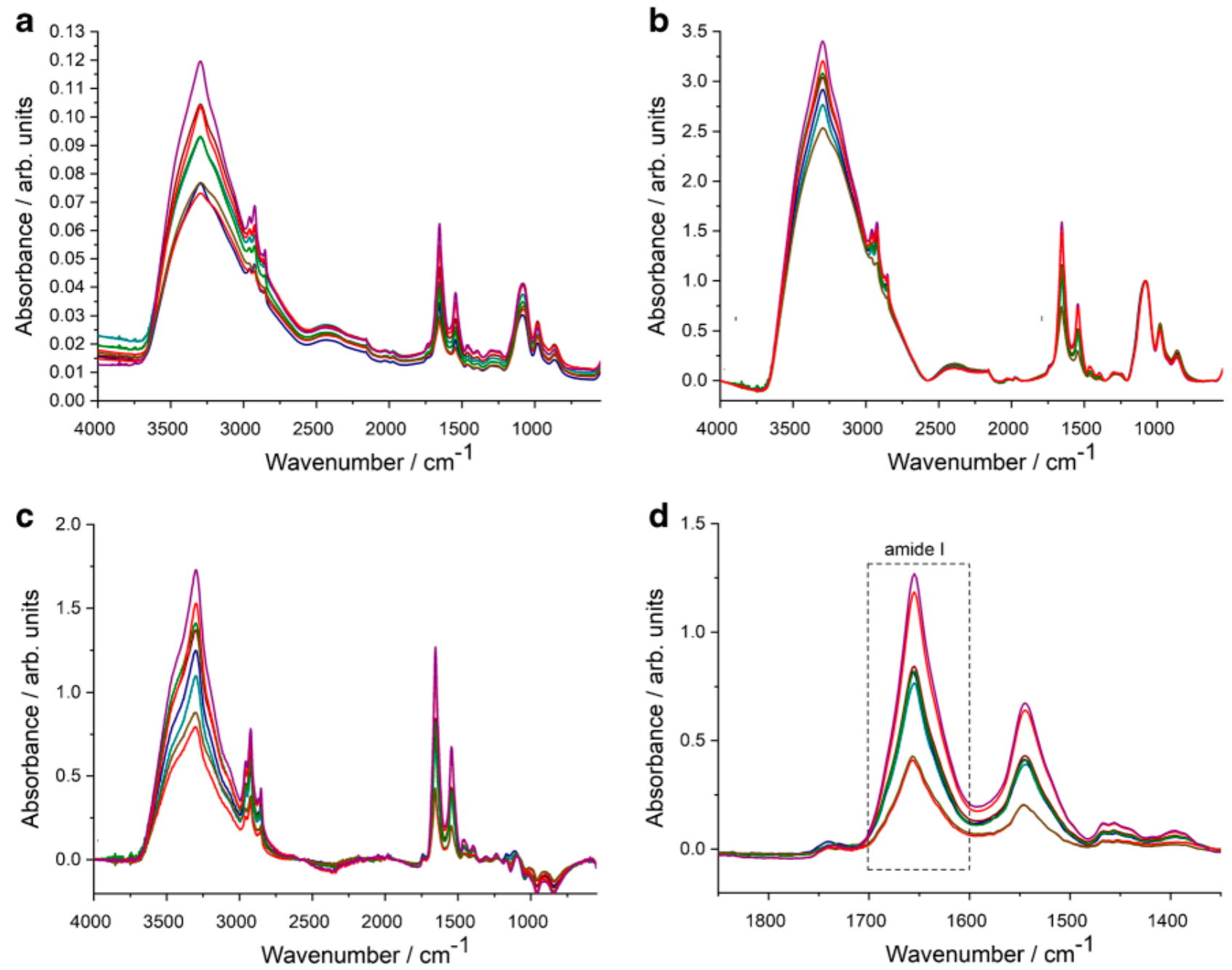

Figure 8. ATR-FTIR spectroscopy quantifies the protein content of extracellular vesicles (EV) samples. (a) Raw absorbance spectra after ATR correction. (b) Absorbance spectra after baseline correction and normalisation. (c) Absorbance spectra after buffer subtraction. (d) Zoomed absorbance spectra for calculating area under the curve (AUC) values of the amide I band by integration in $1700 \mathrm{~cm}^{-1}-1600 \mathrm{~cm}^{-1}$ wavenumber region. Reprinted from [41], SpringerLink, under a Creative Commons Attribution 4.0 International License.

Thus, the differences between the FTIR spectral profile of leukemic and normal serum may offer a potential route to the early identification of children with BCP-ALL, limiting the number of invasive procedures and accelerating the diagnosis of individuals. The possibility of the early detection of leukaemia in children based only on the FTIR analysis of their serum seems an attractive tool for routine medical practice [42]. 


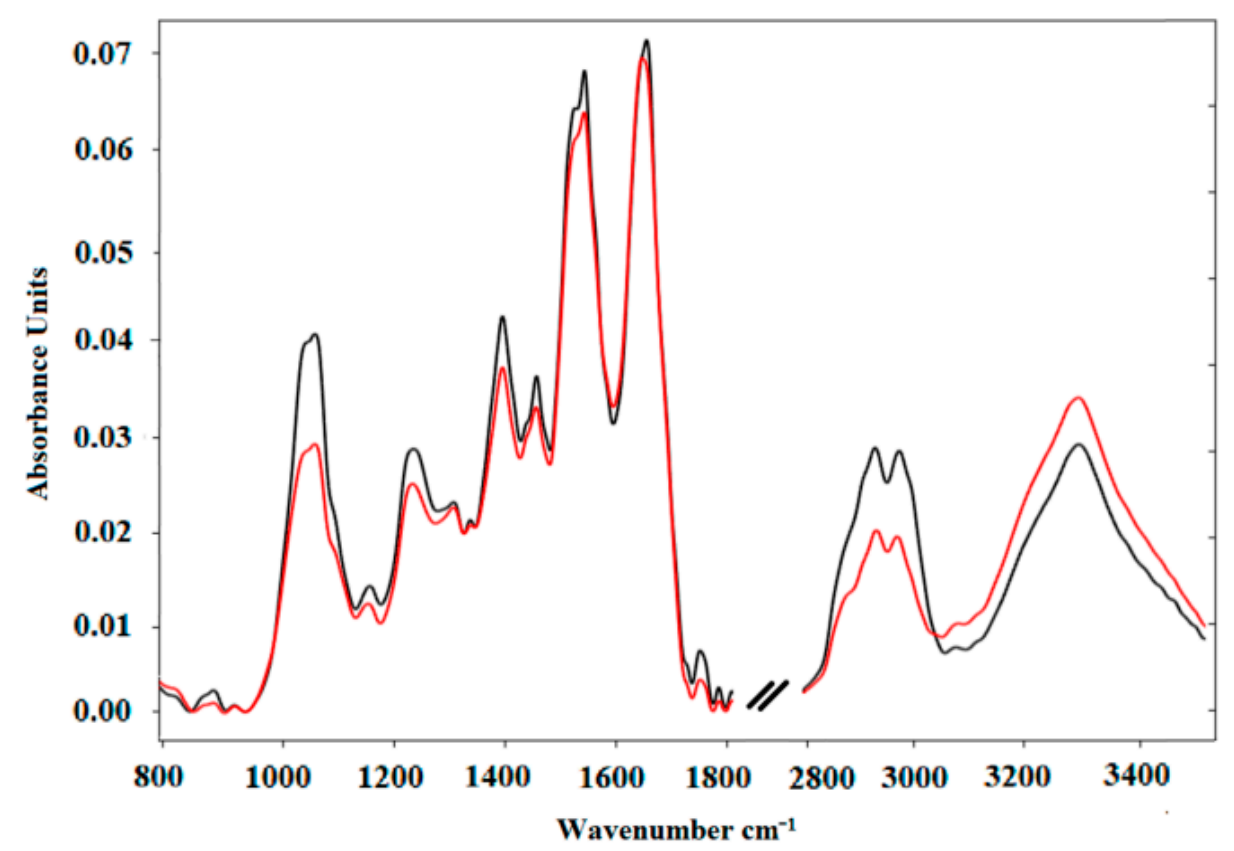

Figure 9. FTIR as a tool for detecting BCP-ALL biomarkers for early screening of pediatric leukaemia. Normalised average FTIR spectra of serum samples: control (black) and Acute Lymphoblastic Leukemia Precursor B (red). The presented spectra cover the range of $800 \mathrm{~cm}^{-1}-3500 \mathrm{~cm}^{-1}$. Reprinted from [42], MDPI, under a Creative Commons Attribution (CC BY) license.

\subsection{Applications of FTIR Spectroscopy in HIV Early Detection}

In 2020, ATR-FTIR spectroscopy was considered for distinguishing HIV-infected patients from healthy uninfected controls [43]. This study comprised one hundred and twenty blood plasma samples of pregnant women and allowed to obtain good sensitivity $(83 \%)$ and specificity $(95 \%)$ using a genetic set of rules with linear discriminant assessment (GA-LDA). In the range of $1800 \mathrm{~cm}^{-1}$ to $900 \mathrm{~cm}^{-1}$, the spectra displayed some particular feature absorptions, including the amide I band at $1635 \mathrm{~cm}^{-1}$, an arm at $1560 \mathrm{~cm}^{-1}$ (due to $\mathrm{C}=\mathrm{O}$, Amide II) and three small depth absorptions at $1480 \mathrm{~cm}^{-1}$ (corresponding to the $\mathrm{C}-\mathrm{H}$ asymmetric deformation of methyl agencies), at $1404 \mathrm{~cm}^{-1}$ (due to the COO-symmetric stretching of proteins and lipids) and $1060 \mathrm{~cm}^{-1}$ (due to the C-O nucleic acids). Due to the similarity between the spectral features in the groups (uninfected control and HIV infected), chemometric patterns were used to identify spectral features responsible for class differentiation Figure 10. ATR-FTIR spectroscopy with multivariate analysis was able to accurately identify HIV-infected pregnant women based on blood plasma, showing the potential of this method for early detection of HIV in a fast and reagent-free approach. Successful development of this method in a clinical environment could aid early diagnosis of gestational HIV and help treatment [43]. 

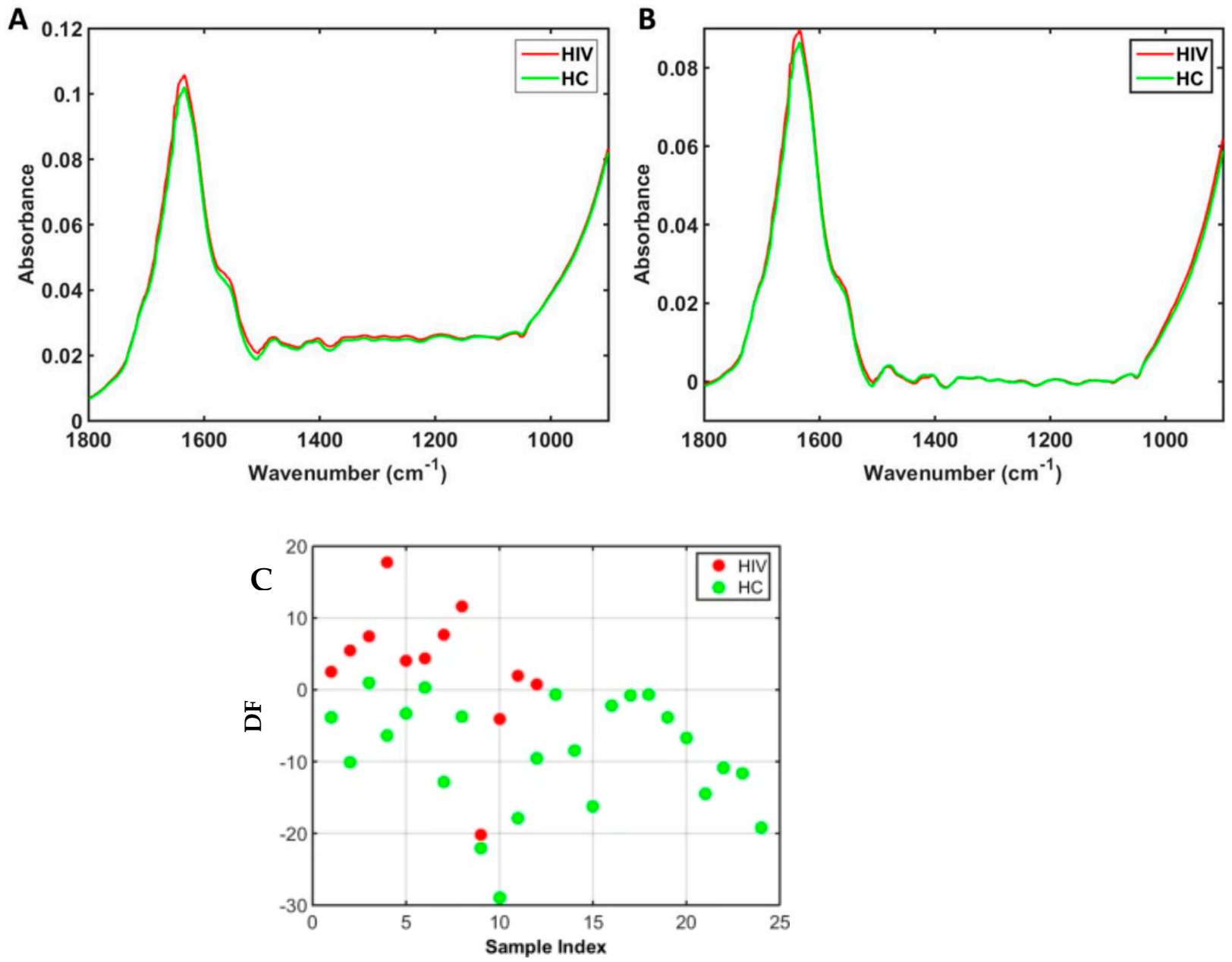

Figure 10. ATR-FTIR spectra for distinguishing between HIV infected and healthy blood samples. (A) Mean raw IR spectra in the biofingerprint region $\left(1800 \mathrm{~cm}^{-1}-900 \mathrm{~cm}^{-1}\right)$ for HIV-infected (HIV) and healthy uninfected controls (HC) samples. (B) Mean preprocessed IR spectra (AWLS baseline correction) in the biofingerprint region $\left(1800 \mathrm{~cm}^{-1}-900 \mathrm{~cm}^{-1}\right)$ for HIV-infected (HIV) and healthy uninfected controls (HC) samples. (C) Discriminant function (DF) for the samples in the test set, where HIV stands for HIV-infected samples and HC for healthy uninfected controls, allowing their distinction. Reprinted from [43], Nature, under a Creative Commons Attribution 4.0 International License.

\subsection{Applications of FTIR Spectroscopy in Blood Grouping Analysis}

In 2017, a study explored the potential for the spectroscopic identification of blood antigens using an FTIR spectrophotometer (Shimadzu FTIR-8400S) within the range of $4000 \mathrm{~cm}^{-1}$ to $400 \mathrm{~cm}^{-1}$ [44]. The ABO blood type system is reflected in the FTIR spectra of human blood. Specific bands at $1166 \mathrm{~cm}^{-1}$ and $1020 \mathrm{~cm}^{-1}$ represent the fucose molecules linked glycosidically with galactose and -GlcNAc-, respectively, related to the $\mathrm{O}$ antigen.

When -GalNAc- is linked to -O antigen- through glycoside linkage, it exhibits a band at $1022 \mathrm{~cm}^{-1}$, due to the $-\mathrm{A}$ antigen-. A band at $1166 \mathrm{~cm}^{-1}$ reveals additional galactose glycosidically bonded to -O antigen-, as seen in Table 2. Summarily, the IR spectroscopic data on human blood of groups $\mathrm{A}, \mathrm{B}, \mathrm{AB}$, and $\mathrm{O}$ explores the possibility of the nonlabelled and reagent free identification of blood antigens using FTIR [44]. 
Table 2. Characteristic FTIR spectral data of human blood antigens (a-antigen) for blood grouping applications [44]. Reprinted with permission from the authors and the International Journal of Science, Environment and Technology.

\begin{tabular}{ccccc}
\hline & \multicolumn{2}{c}{ a } & & Functional Groups \\
\cline { 1 - 3 } A & B & AB & O & Fucose linked to galactose via glycosidic linkage \\
\hline 1166 & 1166 & 1166 & 1163 & Fucose residues linked to GlcNAc via glycosidic linkage \\
\hline 1022 & 1020 & 1022 & 1020 & GalNAc glycosidically bonded to O antigen \\
\hline 1022 & - & 1022 & - & Additional Galactose glycosidically bonded to O antigen \\
\hline- & 1166 & 1166 & - &
\end{tabular}

\subsection{Applications of FTIR Spectroscopy in Blood Analysis}

FTIR spectroscopy has also been considered in human blood analysis [13]. In 2004, a study presented a novel methodology for predicting the health status using FTIR-MC (micro-spectroscopy) data on blood components. In this study, FTIR-MC was complemented by cluster analysis algorithms (i.e., the task of grouping a set of objects in such a way that objects in the same group are more similar to each other than to those in other groups) [45]. The FTIR microscopic spectra of the major blood components, which include white blood cells (WBCs), red blood cells (RBCs), and plasma, were isolated from ten controls (average population). All the spectra were normalised to the amide I peak at $1643 \mathrm{~cm}^{-1}$.

The results reported by the authors showed that there are spectral variations between the three blood components to evaluate the validity of the method. Cluster analysis of the WBCs spectra in the $945 \mathrm{~cm}^{-1}$ to $1282 \mathrm{~cm}^{-1}$ range (comprises both symmetric and asymmetric regions of phosphate) and, more particularly, in the more specific range, from $1146 \mathrm{~cm}^{-1}$ to $1282 \mathrm{~cm}^{-1}$, provided similar results, as shown in Figure 11a,b. The predictions (FTIR has also been used to analyse the body fluids for diagnostic and characterisation) matched the physician's diagnosis with $100 \%$ accuracy, proving the FTIR-MC as a potential tool to predict the health status of blood samples [45].



(a)

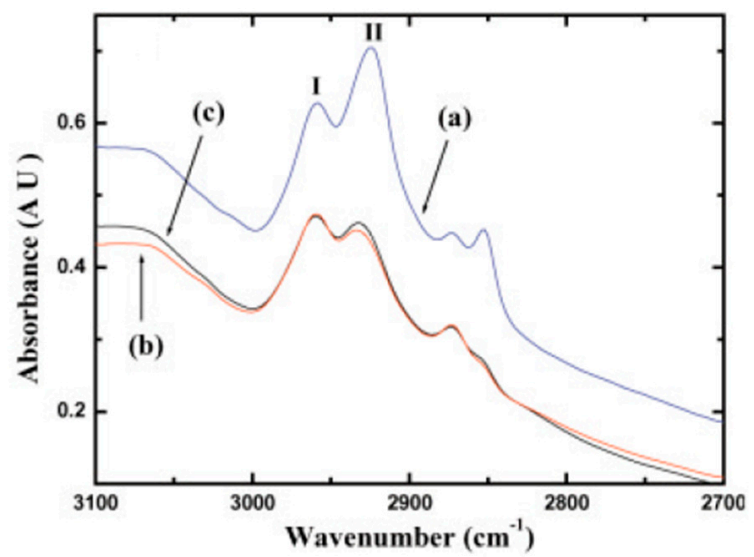

(b)

Figure 11. FTIR spectra of the major blood components: WBCs, RBCs and plasma, aiming for blood analysis. (a) Expanded region of FTIR-MC spectra $\left(900-1500 \mathrm{~cm}^{-1}\right)$ displaying the spectral differences in the symmetric and asymmetric stretching regions of the phosphate group, obtained by the average of ten representative controls; (b) FTIR-MSP spectra of the blood components of the averages of 10 representative controls in the $2700-3100 \mathrm{~cm}^{-1}$ region. (a) WBCs (blue); (b) RBCs (red); (c) Plasma (black) [45]. Adapted from [45] with permission from Wiley. 
Summarily, FTIR-MC can distinguish between the three main components of blood using spectral variations and cluster analysis. Specific spectral changes were observed between infected patients and age-matched healthy controls, providing good classification [45].

\subsection{Other Applications of FTIR Spectroscopy in the Biological Field}

Table 3 presents applications for the FTIR in the biological field tackled rather than blood cell distinction. As observed, FTIR is widely used in biology applications due to its potential to distinguish between different types of molecules.

Table 3. Examples of applications of FTIR in the biological field.

\begin{tabular}{|c|c|c|c|c|c|}
\hline Authors & FTIR Technique & Sample & Analytes & Application & Ref. \\
\hline L. M. Rodrigues et al. & micro-FTIR & $\begin{array}{l}\text { lesions and normal } \\
\text { oral mucosa }\end{array}$ & $\begin{array}{l}\text { collagen, lipids, fat acids, } \\
\text { proteins, and amino acids }\end{array}$ & Evaluation of inflammatory & [46] \\
\hline M. Pachetti et al. & ATR-FTIR & sperm & $\begin{array}{c}\text { Proteins ( } \alpha \text {-helix, } \\
\beta \text {-structures) and lipids }\end{array}$ & $\begin{array}{l}\text { Reveal Lipid and Protein } \\
\text { Changes Induced on Sperm } \\
\text { by Capacitation }\end{array}$ & [47] \\
\hline S. HamanBayarı et al. & ATR-FTIR & archaeological bone & $\begin{array}{l}\text { carbonation of } \\
\text { a phosphate }\end{array}$ & $\begin{array}{l}\text { discrimination of human } \\
\text { bone remains }\end{array}$ & [48] \\
\hline A. Rutter et al. & FTIR & $\begin{array}{c}\text { peripheral blood } \\
\text { mononuclear cells, a } \\
\text { leukaemia cell line, and } \\
\text { a lung cancer cell line }\end{array}$ & lipids & $\begin{array}{l}\text { Identification of a Glass } \\
\text { Substrate to Study Cells }\end{array}$ & [49] \\
\hline R. Minnes et al. & ATR-FTIR & $\begin{array}{l}\text { mouse and human } \\
\text { melanoma cells }\end{array}$ & amide II & $\begin{array}{c}\text { distinguish between } \\
\text { melanoma cells with a } \\
\text { different metastatic potential }\end{array}$ & [50] \\
\hline M. Polakovs et al. & EPR and FTIR & blood & $g$-factor In Methemoglobin & $\begin{array}{l}\text { Study of Human Blood } \\
\text { after Irradiation }\end{array}$ & [51] \\
\hline P. Zarnowiec et al. & FTIR & human bacteria & Protein & $\begin{array}{l}\text { Identification and } \\
\text { Differentiation of } \\
\text { Pathogenic Bacteria }\end{array}$ & [52] \\
\hline M. J. Baker et al. & FTIR & blood & $\begin{array}{l}\text { lipids, proteins, } \\
\text { carbohydrate, and } \\
\text { nucleic acids }\end{array}$ & Analyse biological materials & [53] \\
\hline S. Mordechai et al. & FTIR & $\begin{array}{l}\text { white blood cells } \\
\text { (WBCs) and plasma }\end{array}$ & Protein and amino acids & $\begin{array}{l}\text { Early diagnosis of } \\
\text { Alzheimer's disease }\end{array}$ & [54] \\
\hline M. Martin et al. & ATR-FTIR & $\begin{array}{l}\text { plasma and } \\
\text { whole blood }\end{array}$ & $\begin{array}{l}\text { proteins, nucleic acids, } \\
\text { lipids, and carbohydrates }\end{array}$ & $\begin{array}{l}\text { The effect of common } \\
\text { anticoagulants in detection } \\
\text { and quantification of malaria } \\
\text { parasitemia in human red } \\
\text { blood cells }\end{array}$ & [55] \\
\hline I. C. C. Ferreira et al. & ATR-FTIR & saliva & $\begin{array}{c}\text { proteins, nucleic acids, } \\
\text { lipids, and carbohydrates }\end{array}$ & $\begin{array}{l}\text { Analysis of Saliva for Breast } \\
\text { Cancer Diagnosis }\end{array}$ & [56] \\
\hline C. Aksoy et al. & FTIR spectroscopy and imaging & stem cells & $\begin{array}{l}\text { lipids, proteins, glycogen, } \\
\text { and nucleic acids }\end{array}$ & $\begin{array}{l}\text { Effect of the donor age on } \\
\text { human bone marrow } \\
\text { mesenchymal stem cells }\end{array}$ & [57] \\
\hline V. Shapaval et al. & FTIR & $\begin{array}{l}\text { food-related fungal } \\
\text { strains cultures }\end{array}$ & $\begin{array}{l}\text { fungi detection through } \\
\text { protein quantification }\end{array}$ & $\begin{array}{l}\text { Characterisation of food } \\
\text { spoilage fungi }\end{array}$ & [58] \\
\hline G. Güler et al. & ATR-FTIR & $\begin{array}{l}\text { prostate cancer } \\
\text { stem cells }\end{array}$ & $\begin{array}{l}\text { Protein, nucleic acid, lipid, } \\
\text { and carbohydrate }\end{array}$ & $\begin{array}{l}\text { CD133+/ CD 44+ human } \\
\text { prostate cancer stem cells }\end{array}$ & [59] \\
\hline
\end{tabular}

\subsection{Applications of FTIR Spectroscopy Integrated with Lab-on-a-Chip Devices}

Besides the macroscale FTIR applications, it has also been introduced into many modern technologies. In particular, lab-on-a-chip is a technology that has revolutionised and continues to revolutionise the medical field [60]. It intends to convert health care equipment into small devices that can be applied as point-of-care $(\mathrm{PoC})$ methods for monitoring proposes. There are several examples in the literature of the combination of IR radiation and lab-on-achip technology [61]. Figure 12 presents an example of a pseudo-continuous flow FTIR system integrated on a microfluidic device for sugar identification [61]. Furthermore, the literature has already reported other miniaturised systems based on $\mu$ FTIR for biological applications. 


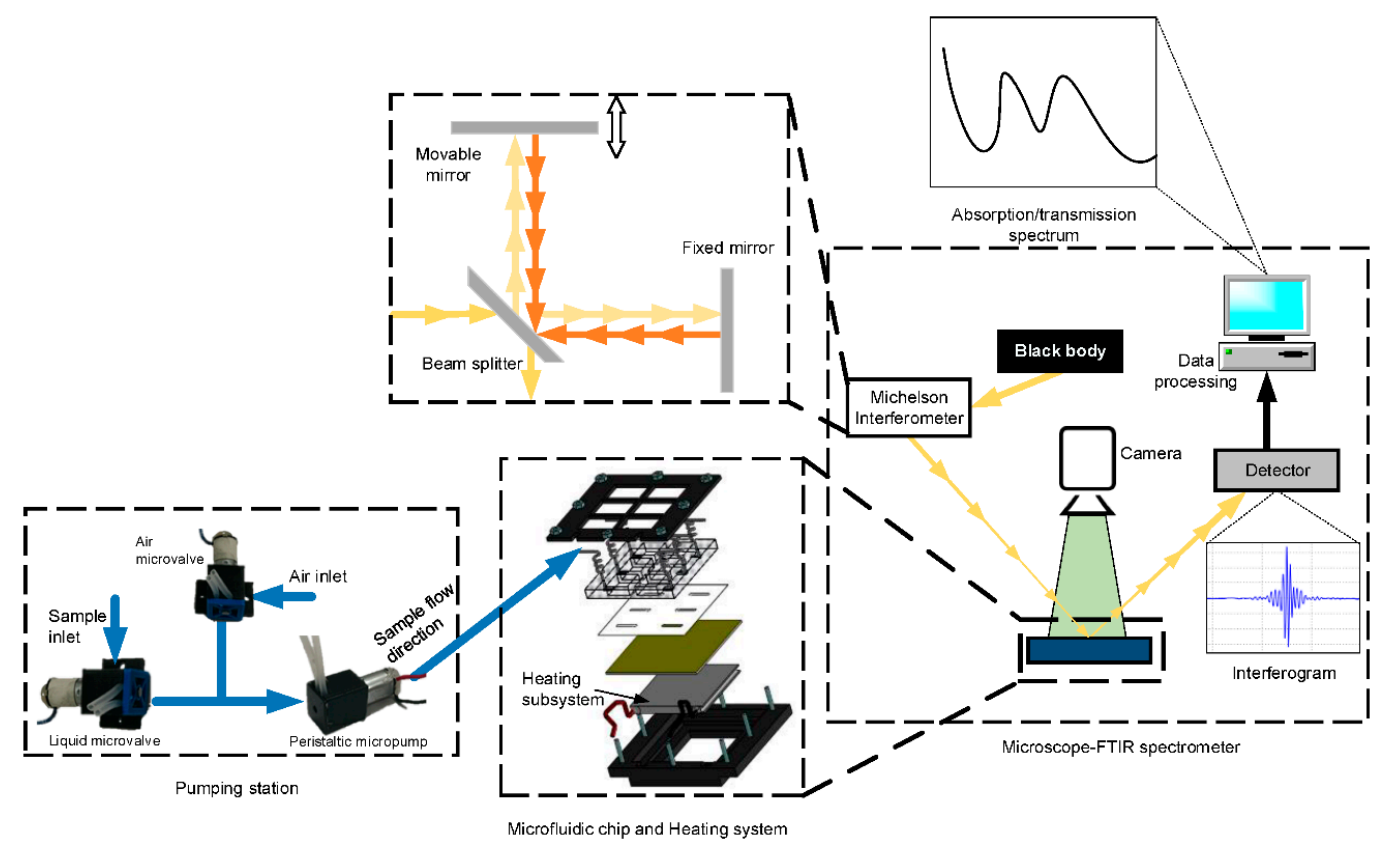

Figure 12. Schematic of the working principle of a pseudo-continuous flow FTIR system, integrated on a microfluidic device for sugar identification. The system includes a pumping station, a microfluidic device, a heating system (for temperature control), and a microscope-FTIR spectrometer. Reprinted from [61], MDPI, under a Creative Commons Attribution (CC BY) license.

A study reported by G. Birarda et al. [62] demonstrated a protocol to build a low-cost IR-Live microfluidic chip for real-time 2D infrared imaging of living cells or tissues with a resolution in the range of micrometres. In this study, FTIR compatible microfluidic chips were produced by direct photolithography of a resist layer coated onto one large IR window (40 mm diameter), with an inlet connected to a tubing system and an outlet attached to a circular reservoir [62]. In the centre of the device, there is an IR-transparent experimental chamber sandwiched between two $\mathrm{CaF}_{2}$ crystal discs. The results of IR imaging on migrating cells with the subcellular spatial resolution can distinguish different cellular organelles and identify their peculiar chemical composition at a functional group level. The authors, through the performed assays $(n=14)$, were able to show the characteristic shapes of the proteins (amide II bands) and lipids $\left(\mathrm{CH}_{2}-\mathrm{CH}_{3}\right.$ stretching) in the cells. The spectrum has a sharp protein signal centred at $1654 \mathrm{~cm}^{-1}$, mainly attributed to an $\alpha$-helix protein structure [62].

Another method was developed for rapid ATR-FTIR monitoring solute concentrations in solutions flowing through microchannels [63]. The method involves the interface of commercially available ATR-FTIR instrumentation with a customised microfluidic device, which is sufficiently robust to withstand flow rates of the liquids of at least $20 \mathrm{~mL} \mathrm{~h}^{-1}$. The authors reported that the paper opened the way for on-chip identification of chemical compounds, measurements of their concentrations in solutions, and studies of reaction kinetics. Furthermore, the method can be used to characterise the adsorption of chemical and biological species adsorbed on the ATR surface under flow. From the spectrum in the region of $1400 \mathrm{~cm}^{-1}-900 \mathrm{~cm}^{-1}$, the authors reported peaks at $1100 \mathrm{~cm}^{-1}$ and $1250 \mathrm{~cm}^{-1}$, which correspond to the antisymmetric and symmetric vibrational modes of the COC groups, respectively, and a peek at $950 \mathrm{~cm}^{-1}$, which is from the $C=C$ bonds in its phenyl ring. The authors also focused on the dominant band at $1100 \mathrm{~cm}^{-1}$ and plotted the variation of its absorbance vs. concentration of TX-100 (CTX-100) in the solution. For CTX-100 $\geq 5 \mathrm{mM}$, the absorbance of the band linearly increased with the increasing solute concentration. According to the authors, the method allows the rapid acquisition of spectra and enables chemical characterisation and concentration measurements independent of the flow rate of liquids. The method enables the independent measurement of concentrations 
of solutes with distinct spectral features in mixed solutions. For the polymer solutes, the authors report that the method has a sensitivity of at least $10 \mu \mathrm{M}(0.01 \mathrm{wt} \%)$. The authors also proposed the method's applicability for the differentiation between dissolved and adsorbed amphiphilic species [63].

\section{Conclusions}

In this review paper, among the various spectroscopic techniques developed, FTIR is presented as a technique with the potential for distinguishing healthy from pathological samples. Numerous works have used FTIR with other techniques, such as ATR or microFTIR, to improve and simplify the spectral result of FTIR spectroscopy. The ATR-FTIR method promises the potential for the study of cells and tissues in general and, in particular, as a tool for estimating the metastatic potential of cancer cells. ATR-FTIR spectroscopy was also able to accurately identify HIV-infected pregnant women based on blood plasma, demonstrating the potential of this method for early detection of HIV in a rapid and reagent-free approach.

Label-free FTIR spectroscopy allows greater accuracy and reproducibility in cancer diagnosis while eliminating the need for complex and time-consuming clinical processing of tissue samples, currently required by existing computerised histopathological diagnosis. In addition, FTIR spectroscopy has also shown the potential to rapidly and objectively evaluate surgical resection margins to aid in surgical decision making, which may improve longterm survival and postoperative patient recovery compared with standard intraoperative pathological examination.

FTIR has also been used to monitor the response to cancer treatments and followup patients for treatment planning, early detection of recurrence, and assistance with psychological or psychosocial distress, with results that are faster, more sensitive, and more specific than conventional methods. Therefore, FTIR spectroscopy would be crucial to accelerate point-of-care decisions and potentially revolutionise cancer diagnostics in personalised medicine.

FTIR is the future measurement technique that shows tremendous potential and effective solutions to a large number of diagnostic complexities now faced by medical professionals. For instance, due to the limitations of the current gold standard techniques, FTIR may be advantageous to distinguish between normal samples and cancerous samples at an early stage, which offers the chance to diagnose and treat samples before any symptoms appear in patients. All these advantages force the researchers to dive deep into FTIR technology to move from a recognised to a viable technique used in the biological field, as in the other fields (environmental and chemical engineering, for instance) that are already recruiting FTIR for several applications.

\section{Future Trends}

Although FTIR is in continuous development in the biology field, the number of studies focusing on topics within the FTIR framework is steadily growing. In the future, FTIR may have a significant impact on various aspects of the medical field (i.e., hospital design, lab technician practices), including the financial. FTIR might bypass much equipment currently in use, as well as a large number of reagents used to perform the blood tests, thus proving to be a fast, convenient, economical, practical, and accurate method with high-quality results and minor environmental impact. However, to the best of the authors' knowledge, despite the great interest of the scientific community in FTIR, there are only a few microdevice platforms reported in the literature. Lab-on-a-chip devices, with integrated ATR-FTIR measurements for medical applications in real-time label-free living biological systems analysis, deal with the problem of water presence, either using cell culture medium, plasma, or serum samples, once the absorption values could overlap the bands of other components [64]. In this perspective, ATR-FTIR is the best option to be integrated to study both hydrated and dried biological samples, such as cells and fluid flow [64]. Specifically, in the field of biomechanics and living mechanobiology, ATR-FTIR spectroscopy visualisation 
and quantification have also been demonstrated to be an excellent method for nondestructive biological analysis. Apart from all the cancer diagnostics biomarkers discussed in this work, cells' alterations related to diseases occur in most blood pathologies associated with mechanical and rheological changes. The detection and quantification of mechanical alterations have hundreds of applications in diverse fields, ranging from the analysis of cell biomechanics to the classification of tissue biopsies [64-66]. For example, mechanical differences in exosomes and microvesicles reflect changes in cell biomechanics and the cell type, state, treatment, and phenotype [66]. Thus, their quantification and analysis are important for diseases stratification and personalised medicine, showing ATR-FTIR as an advantageous strategy.

Another example is the RBC deformability analysis that is affected by several factors, such as ageing, high blood sugar levels, total cholesterol, or functional oxidative stress. Thus, their membrane and internal cytoplasm suffer changes which biochemical analysis (particularly ATR-FTIR) with morphological and rheological techniques can define and then provide a profile indicative of deformability alteration [67]. As ATR-FTIR technology for blood or body fluids analysis requires proper sample preparation, integration of microfluidics can play, once more, an important role in the development of strategies for sample preparation, such as cells or plasma separation devices, single-cell sorting, cell deformability devices, droplet generators, and cell traps, among others. It is known that spectral analysis demonstrated that deeply deformed cells have different cellular biochemistry compared to nondeformed ones. So, it is expected that significant improvements can be obtained by integrating sample preparation microfluidic systems, enabling the RBCs, white blood cells, or circulating tumour cells analysis, in terms of their membrane biochemical quantification and consequently their biomechanical behaviour [68]. Looking forward to applications in tumour-on-a-chip devices, transparent 3D microfluidic devices will allow ATR-FTIR microspectroscopy applications to monitor the biochemical response to both mechanical and chemical stimulations (i.e., drug resistance).

The development of such devices will be a step ahead in state of the art and will overcome the limitations of current technologies. Thus, to achieve such a goal, future works need to consider the design, fabrication, characterisation, and optimisation of lab-on-a-chip platforms, with IR radiation and Fourier Transform postprocessing, to examine blood cells, distinguishing between normal and pathological ones, and to better understand several mechanisms of treatment resistance and progression.

Author Contributions: Conceptualization, A.F., V.H.C. and G.M.; methodology, A.F., V.H.C., S.O.C. and G.M.; investigation, A.F., D.P., V.H.C., S.O.C. and G.M.; writing—original draft preparation, A.F.; writing - review and editing, D.P., V.H.C., S.O.C. and G.M.; supervision, V.H.C., S.O.C. and G.M.; funding acquisition, S.O.C. and G.M. All authors have read and agreed to the published version of the manuscript.

Funding: This work results of the projects NORTE-01-0145-FEDER-029394, RTChip4Theranostics, and NORTE-01-0145-FEDER-028178, MalariaChip, supported by Programa Operacional Regional do Norte-Norte Portugal Regional Operational Programme (NORTE 2020), under the PORTUGAL 2020 Partnership Agreement, through the European Regional Development Fund (FEDER) and by Fundação para a Ciência e Tecnologia (FCT), IP, projects reference PTDC/EMD-EMD/29394/2017 and PTDC/EEI-EEE/28178/2017. The authors also acknowledge the partial financial support by FCT national funds, under the national support to R\&D units grant, through the reference project UIDB/04436/2020, UIDP/04436/2020 and UID/CEC/00319/2020. Susana Catarino thanks FCT for her contract funding provided through 2020.00215.CEECIND.

Data Availability Statement: Not applicable.

Conflicts of Interest: The authors declare no conflict of interest. The funders had no role in the design of the study; in the collection, analyses, or interpretation of data; in the writing of the manuscript, or in the decision to publish the results. 


\section{References}

1. O'Sullivan, J.W.; Stevens, S.; Hobbs, F.D.R.; Salisbury, C.; Little, P.; Goldacre, B.; Bankhead, C.; Aronson, J.K.; Perera, R.; Heneghan, C. Temporal trends in use of tests in UK primary care, 2000-2015: Retrospective analysis of 250 million tests. BMJ 2018, 363 , k4666. [CrossRef] [PubMed]

2. National Academies of Sciences, Engineering, and Medicine. Improving Diagnosis in Health Care; National Academies Press: Washington, DC, USA, 2015. [CrossRef]

3. Rohde, T.; Martinez, R. Equipment and Energy Usage in a Large Teaching Hospital in Norway. J. Healthc. Eng. 2015, 6, 419-434. [CrossRef] [PubMed]

4. Pati, H.P.; Singh, G. Turnaround Time (TAT): Difference in Concept for Laboratory and Clinician. Indian J. Hematol. Blood Transfus. 2012, 30, 81-84. [CrossRef] [PubMed]

5. National Research Council (US) Committee on Prudent Practices in the Laboratory. Prudent Practices in the Laboratory: Handling and Management of Chemical Hazards: Updated Version; National Academies Press (US): Washington, DC, USA, 2011. Available online: https:/ / www.ncbi.nlm.nih.gov/books/NBK55878 / (accessed on 1 June 2021). [CrossRef]

6. Luppa, P.B.; Müller, C.; Schlichtiger, A.; Schlebusch, H. Point-of-care testing (POCT): Current techniques and future perspectives. Trends Anal. Chem. 2011, 30, 887-898. [CrossRef] [PubMed]

7. Cole, L.; Kramer, P.R. Bacteria, Virus, Fungi, and Infectious Diseases. In Human Physiology, Biochemistry and Basic Medicine; Academic Press: Cambridge, MA, USA, 2016; pp. 193-196. [CrossRef]

8. Morris, R. Spectrophotometry. Curr. Protoc. Essent. Lab. Tech. 2015, 11, 2.1.1-2.1.30. [CrossRef]

9. Olaniyan, M.F. Lecture Notes on Laboratory Instrumentation and Techniques, 1st ed.; Achievers University: Owo-Nigeria, Nigeria, 2017; pp. 1-244.

10. Orange County Biotechnology Education Collaborative, "Introduction to Biotechnology", LibreTexts. 2013, pp. 1-148. Available online: https:/ / batch.libretexts.org/print/Letter/Finished/bio-36736/Full.pdf (accessed on 1 July 2021).

11. How an Automated Blood Cell Counter Works? Medsource Ozone Biomedicals. 2020. Available online: https://www.ozonebio. $\mathrm{com} /$ india/product-detail/alphacount-60\#insights (accessed on 1 July 2021).

12. Diem, M.; Chiriboga, L.; Lasch, P.; Pacifio, A. IR spectra and IR spectral maps of individual normal and cancerous cells. Biopolymers 2002, 67, 349-353. [CrossRef]

13. Byrne, H.J.; Bonnier, F.; McIntyre, J.; Parachalil, D.R. Quantitative analysis of human blood serum using vibrational spectroscopy. Clin. Spectrosc. 2020, 2, 100004. [CrossRef]

14. Griffiths, P.R.; de Haseth, J.A. Fourier Transform Infrared Spectrometry; John Wiley \& Sons: New York, NY, USA, 1986.

15. Mantsch, H.H.; Chapman, D. Infrared Spectroscopy of Biomolecules; John Wiley \& Sons Inc.: New York, NY, USA, 1996.

16. Cooper, E.A.; Knutson, K. Fourier transform infrared spectroscopy investigations of protein structure. Vaccine Des. 1995, 7, 101-143.

17. Liquier, J.; Taillandier, E. Infrared spectroscopy of nucleic acids. In Infrared Spectroscopy of Biomolecules; Mantsch, H.H., Chapman, D., Eds.; Wiley-Liss: New York, NY, USA, 1996; pp. 131-158.

18. Banyay, M.; Sarkar, M.; Graslund, A. A library of IR bands of nucleic acids in solution. Biophys. Chem. 2003, 104, 477-488. [CrossRef]

19. Brandenburg, K.; Seydel, U. Infrared spectroscopy of glycolipids. Chem. Phys. Lipids 1998, 96, 23-40. [CrossRef]

20. Mostaço-Guidolin, L.B.; Murakami, L.S.; Nomizo, A.; Bachmann, L. Fourier transform infrared spectroscopy of skin cancer cells and tissues. Appl. Spectros. Rev. 2009, 44, 438-455. [CrossRef]

21. Gremlich, H.U. Infrared and Raman Spectroscopy of Biological Materials; Marcel Dekker: New York, NY, USA, 2001.

22. Near, Mid and Far-Infrared (dur.ac.uk), Infrared Processing and Analysis Center, NASA Official: Brian Dunbar. 10 April 2009 Available online: http://www.icc.dur.ac.uk/ \{\}tt/Lectures/Galaxies/Images/Infrared/Regions/irregions.html (accessed on 1 June 2021).

23. Balan, V.; Mihai, C.T.; Cojocaru, F.D.; Uritu, C.M.; Dodi, G.; Botezat, D.; Gardikiotis, I. Vibrational Spectroscopy Fingerprinting in Medicine: From Molecular to Clinical Practice. Materials 2019, 12, 2884. [CrossRef] [PubMed]

24. Bramson, M.A. Infrared Radiation: A Handbook for Applications; Springer: New York, NY, USA, 1968.

25. Talari, A.C.S.; Martinez, M.A.G.; Movasaghi, Z.; Rehman, S.; Rehman, I.U. Advances in Fourier transform infrared (FTIR) spectroscopy of biological tissues. Appl. Spectrosc. Rev. 2017, 52, 456-506. [CrossRef]

26. Movasaghi, Z.; Rehman, S.; Rehman, I.U. Fourier Transform Infrared (FTIR) Spectroscopy of Biological Tissues. Appl. Spectrosc. Rev. 2008, 43, 134-179. [CrossRef]

27. Barth, A. Infrared spectroscopy of proteins. Biochim. Biophys. Acta Bioenerg. 2007, 1767, 1073-1101. [CrossRef] [PubMed]

28. Fringeli, V.P. Membrane Spectroscopy; Springer: New York, NY, USA, 1981.

29. Casal, H.L.; Mantsch, H.H. Polymorphic phase behaviour of phospholipid membranes studied by infrared spectroscopy. Biochim. Biophys. Acta Rev. Biomembr. 1984, 779, 381-401. [CrossRef]

30. Siebert, P.H.F. Vibrational Spectroscopy in Life Science; John Wiley \& Sons: Berlin/Heidelberg, Germany, 2008.

31. Wiercigroch, E.; Szafraniec, E.; Czamara, K.; Pacia, M.Z.; Majzner, K.; Kochan, K.; Kaczor, A.; Baranska, M.; Malek, K. Raman and infrared spectroscopy of carbohydrates: A review. Spectrochim. Acta Part A Mol. Biomol. Spectrosc. 2017, 185, 317-335. [CrossRef] [PubMed] 
32. Chai, J.; Zhang, K.; Xue, Y.; Liu, W.; Chen, T.; Lu, Y.; Zhao, G. Review of MEMS Based Fourier Transform Spectrometers. Micromachines 2020, 11, 214. [CrossRef]

33. Grdadolnik, J. ATR-FTIR Spectroscopy: Its Advantages and Limitations. Acta Chim. Slov. 2002, 49, 631-642.

34. Jelle, B.P.; Nilsen, T.N.; Hovde, P.J.; Gustavsen, A. Accelerated Climate Aging of Building Materials and their Characterization by Fourier Transform Infrared Radiation Analysis. J. Build. Phys. 2012, 36, 99-112. [CrossRef]

35. La Russa, M.F.; Ruffolo, S.A.; Barone, G.; Crisci, G.M.; Mazzoleni, P.; Pezzino, A. The Use of FTIR and Micro-FTIR Spectroscopy: An Example of Application to Cultural Heritage. Int. J. Spectrosc. 2009, 2009, 893528. [CrossRef]

36. Liu, Y.; Yang, Z.; Desyaterik, Y.; Gassman, P.L.; Wang, H.; Laskin, A. Hygroscopic Behavior of Substrate-Deposited Particles Studied by micro-FT-IR Spectroscopy and Complementary Methods of Particle Analysis. Anal. Chem. 2008, 80, 633-642. [CrossRef] [PubMed]

37. Coates, J. Interpretation of Infrared Spectra, A Practical Approach. In Encyclopedia of Analytical Chemistry; Meyers, R.A., McKelvy, M.L., Eds.; John Wiley \& Sons Ltd.: Chichester, UK, 2000. [CrossRef]

38. Prabhakar, S.; Jain, N.; Singh, R.A. FT-IR Spectroscopy as a Bio-Diagnostic Tool for Detection of Leukemia. In Emerging Trends in Laser E Spectroscopy and Applications, 2010th ed.; Allied Publishers: New Delhi, India, 2010; Chapter 40; pp. $337-341$.

39. Ollesch, J.; Theegarten, D.; Altmayer, M.; Darwiche, K.; Hager, T.; Stamatis, G.; Gerwert, K. An infrared spectroscopic blood test for non-small cell lung carcinoma and subtyping into pulmonary squamous cell carcinoma or adenocarcinoma. Biomed. Spectrosc. Imaging 2016, 5, 129-144. [CrossRef]

40. Andleeb, F.; Atiq, A.; Atiq, M.; Malik, S. Attenuated total reflectance spectroscopy to diagnose skin cancer and to distinguish different metastatic potential of melanoma cell. Cancer Biomark. 2018, 23, 373-380. [CrossRef]

41. Szentirmai, V.; Wacha, A.; Németh, C.; Kitka, D.; Rácz, A.; Héberger, K.; Mihály, J.; Varga, Z. Reagent-free total protein quantification of intact extracellular vesicles by attenuated total reflection Fourier transform infrared (ATR-FTIR) spectroscopy. Anal. Bioanal. Chem. 2020, 412, 4619-4628. [CrossRef]

42. Chaber, R.; Kowal, A.; Jakubczyk, P.; Arthur, C.; Łach, K.; Wojnarowska-Nowak, R.; Kusz, K.; Zawlik, I.; Paszek, S.; Cebulski, J. A Preliminary Study of FTIR Spectroscopy as a Potential Non-Invasive Screening Tool for Pediatric Precursor B Lymphoblastic Leukemia. Molecules 2021, 26, 1174. [CrossRef]

43. Silva, L.G.; Péres, A.F.S.; Freitas, D.L.D.; Morais, C.L.M.; Martin, F.L.; Crispim, J.C.O.; Lima, K.M.G. ATR-FTIR spectroscopy in blood plasma combined with multivariate analysis to detect HIV infection in pregnant women. Sci. Rep. 2020, 10, 20156. [CrossRef]

44. Vijaya, U. Ushasree and Adeel Ahmad Ftir Spectroscopic Analysis on Human Blood Groups. Int. J. Sci. Environ. Technol. 2017, 6, 1685-1689. Available online: https:/ / www.ijset.net/journal/1736.pdf (accessed on 1 September 2021).

45. Mordehai, J.; Ramesh, J.; Cohen, Z.; Kleiner, O.; Talyshinsky, M.; Erukhimovitch, V.; Cahana, A.; Salman, A.; Sahu, R.K.; Guterman, H.; et al. Studies on acute human infections using FTIR microspectroscopy and cluster analysis. Biopolymers 2004, 73, 494-502. [CrossRef]

46. Rodrigues, L.M.; Carvalho, L.F.D.C.E.S.; Bonnier, F.; Anbinder, A.L.; Martinho, H.D.S.; Almeida, J.D. Evaluation of inflammatory processes by FTIR spectroscopy. J. Med. Eng. Technol. 2018, 42, 228-235. [CrossRef]

47. Pachetti, M.; Zupin, L.; Venturin, I.; Mitri, E.; Boscolo, R.; D’Amico, F.; Vaccari, L.; Crovella, S.; Ricci, G.; Pascolo, L. FTIR Spectroscopy to Reveal Lipid and Protein Changes Induced on Sperm by Capacitation: Bases for an Improvement of Sample Selection in ART. Int. J. Mol. Sci. 2020, 21, 8659. [CrossRef] [PubMed]

48. Bayarı, S.H.; Özdemir, K.; Sen, E.H.; Araujo-Andrade, C.; Erdal, Y.S. Application of ATR-FTIR spectroscopy and chemo-metrics for the discrimination of human bone remains from different archaeological sites in Turkey. Spectrochim. Acta Part A Mol. Biomol. Spectrosc. 2020, 237, 118311. [CrossRef] [PubMed]

49. Rutter, A.V.; Crees, J.; Wright, H.; Raseta, M.; Van Pittius, D.G.; Roach, P.; Sulé-Suso, J. Identification of a Glass Substrate to Study Cells Using Fourier Transform Infrared Spectroscopy: Are We Closer to Spectral Pathology? Appl. Spectrosc. 2020, 74, 178-186. [CrossRef] [PubMed]

50. Minnes, R.; Nissinmann, M.; Maizels, Y.; Gerlitz, G.; Katzir, A.; Raichlin, Y. Using Attenuated Total Reflection-Fourier Transform Infra-Red (ATR-FTIR) spectroscopy to distinguish between melanoma cells with a different metastatic potential. Sci. Rep. 2017, 7, 4381. [CrossRef]

51. Polakovs, M.; Mironova-Ulmane, N.; Pavlenko, A.; Reinholds, E.; Gavare, M.; Grube, M. EPR and FTIR Spectroscopies Study of Human Blood after Irradiation. Spectroscopy 2012, 27, 367-371. [CrossRef]

52. Zarnowiec, P.; Lechowicz, Ł.; Czerwonka, G.; Kaca, W. Fourier Transform Infrared Spectroscopy (FTIR) as a Tool for the Identification and Differentiation of Pathogenic Bacteria. Curr. Med. Chem. 2015, 22, 1710-1718. [CrossRef]

53. Baker, M.J.; Trevisan, J.; Bassan, P.; Bhargava, R.; Butler, H.J.; Dorling, K.M.; Fielden, P.R.; Fogarty, S.W.; Fullwood, N.J.; Heys, K.A.; et al. Using Fourier transform IR spectroscopy to analyze biological materials. Nat. Protoc. 2014, 9, 1771-1791. [CrossRef]

54. Mordechai, S.; Shufan, E.; Katz, B.S.P.; Salman, A. Early diagnosis of Alzheimer's disease using infrared spectroscopy of isolated blood samples followed by multivariate analyses. Analyst 2017, 142, 1276-1284. [CrossRef]

55. Martin, M.; Perez-Guaita, D.; Andrew, D.W.; Richards, J.S.; Wood, B.R.; Heraud, P. The effect of common anticoagulants in detection and quantification of malaria parasitemia in human red blood cells by ATR-FTIR spectroscopy. Analyst 2017, 142, 1192-1199. [CrossRef] 
56. Ferreira, I.C.C.; Aguiar, E.M.G.; Silva, A.T.F.; Santos, L.L.D.; Cardoso-Sousa, L.; Araújo, T.G.; Santos, D.W.; Goulart, L.R.; SabinoSilva, R.; Maia, Y.C.P. Attenuated Total Reflection-Fourier Transform Infrared (ATR-FTIR) Spectroscopy Analysis of Saliva for Breast Cancer Diagnosis. J. Oncol. 2020, 2020, 4343590. [CrossRef]

57. Aksoy, C.; Çetinkaya, D.U.; Kuşkonmaz, B.B.; Uçkan, D.; Severcan, F. Structural investigation of donor age effect on human bone marrow mesenchymal stem cells: FTIR spectroscopy and imaging. Age 2014, 36, 1-17. [CrossRef] [PubMed]

58. Shapaval, V.; Schmitt, J.; Møretrø, T.; Suso, H.; Skaar, I.; Åsli, A.; Lillehaug, D.; Kohler, A. Characterization of food spoilage fungi by FTIR spectroscopy. J. Appl. Microbiol. 2013, 114, 788-796. [CrossRef] [PubMed]

59. Güler, G.; Guven, U.; Oktem, G. Characterization of CD133+/CD44+ human prostate cancer stem cells with ATR-FTIR spectroscopy. Analyst 2019, 144, 2138-2149. [CrossRef] [PubMed]

60. Stoytcheva, M.; Zlatev, R. Lab on a Chip Fabrication and Application, 1st ed.; InTechOpen: Rijeka, Croatia, 2016; ISBN 978-953-51-2457-3.

61. Landari, H.; Roudjane, M.; Messaddeq, Y.; Miled, A. Pseudo-Continuous Flow FTIR System for Glucose, Fructose and Sucrose Identification in Mid-IR Range. Micromachines 2018, 9, 517. [CrossRef] [PubMed]

62. Birarda, G.; Ravasio, A.; Suryana, M.; Maniam, S.; Holman, H.-Y.N.; Grenci, G. IR-Live: Fabrication of a low-cost plastic microfluidic device for infrared spectromicroscopy of living cells. Lab Chip 2016, 16, 1644-1651. [CrossRef] [PubMed]

63. Greener, J.; Abbasi, B.; Kumacheva, E. Attenuated total reflection Fourier transform infrared spectroscopy for on-chip monitoring of solute concentrations. Lab Chip 2010, 10, 1561-1566. [CrossRef]

64. Sabbatini, S.; Conti, C.; Orilisi, G.; Giorgini, E. Infrared spectroscopy as a new tool for studying single living cells: Is there a niche? Biomed. Spectrosc. Imaging 2017, 6, 85-99. [CrossRef]

65. Edmond, V.; Dufour, F.; Poiroux, G.; Shoji, K.; Malleter, M.; Fouqué, A.; Tauzin, S.; Rimokh, R.; Sergent, O.; Penna, A.; et al. Downregulation of ceramide synthase- 6 during epithelial-to-mesenchymal transition reduces plasma membrane fluidity and cancer cell motility. Oncogene 2015, 34, 996-1005. [CrossRef]

66. Di Santo, R.; Romanò, S.; Mazzini, A.; Jovanović, S.; Nocca, G.; Campi, G.; Papi, M.; De Spirito, M.; Di Giacinto, F.; Ciasca, G. Recent Advances in the Label-Free Characterization of Exosomes for Cancer Liquid Biopsy: From Scattering and Spectroscopy to Nanoindentation and Nanodevices. Nanomaterials 2021, 11, 1476. [CrossRef]

67. Blat, A.; Stepanenko, T.; Bulat, K.; Wajda, A.; Dybas, J.; Mohaissen, T.; Alcicek, F.; Szczesny-Malysiak, E.; Malek, K.; Fedorowicz, A.; et al. Spectroscopic Signature of Red Blood Cells in a D-Galactose-Induced Accelerated Aging Model. Int. J. Mol. Sci. 2021, 22, 2660. [CrossRef]

68. Mitri, E.; Birarda, G.; Vaccari, L.; Kenig, S.; Tormen, M.; Grenci, G. SU-8 bonding protocol for the fabrication of microfluidic devices dedicated to FTIR microspectroscopy of live cells. Lab Chip 2014, 14, 210-218. [CrossRef] [PubMed] 